\title{
Detection of surface subsidence using SAR SENTINEL 1A imagery and the DInSAR method - a case study of the Belchatow open pit mine, Central Poland
}

\author{
Jaroslaw Wajs ${ }^{1, *}$, and Wojciech J. Milczarek ${ }^{1}$ \\ ${ }^{1}$ Wrocław University of Science and Technology, Faculty of Geoengineering, Mining and Geology, 27 Wyb. Wyspiańskiego St., \\ 50-370 Wrocław, Poland
}

\begin{abstract}
Open pit mining hazards monitoring is a crucial task. The paper focuses on the first analysis of surface subsidence in the open pit mining area obtained by Synthetic Aperture Radar active remote sensing technique. Presented methodology of Differential Interferometric SAR provides an excellent data source for mining vertical displacements monitoring. The study was performed in the Belchatow open pit lignite mine in Poland, Central Europe. The SAR SLC imageries acquired by the SENTINEL 1A satellite for the 124-descending track in two periods, between 03.10.2016-15.10.2016 and 15.10.2016-27.10.2016 have been used in the analysis. The post-proceed satellite line of sight (LOS) displacement indicates vertical changes of the surface within the dumping and excavation area. The analyzed region of interests (ROI) shows total subsidence of ca. $-67 \mathrm{~mm}$, whereas the excavation areas show a trend of terrain uplift during the analyzed periods.
\end{abstract}

\section{Introduction}

Monitoring of mining areas with application of land survey methods is the fundamental task of mine surveyors. When performed with the use of classical survey methods, these tasks result in point sampling of the reality by geodetic observation lines and surface sampling using the raster matrix in the analyzed mining area. Three-dimensional modelling of open cast mines determines the spatial coordinates of characteristic terrain objects. Classical measurement methods in mining surveys require time-consuming fieldwork and are loaded with errors of the surveyor related e.g. with ground sampling. The result of the performed investigations is $\mathrm{XY}$ coordinates and their elevation values in an accepted reference system [1]. Fig. 1 presents the comparative analysis of selected active remote sensing sensors as sources of spatial data. This analysis was prepared based on compilation [2]. Remote sensing may be an alternative data source for the spatial database of the open pit lignite mine. Since analyzed object is an open pit mine, the obtained map of terrain subsidence has to base on high temporal, spatial data. These features are characteristic for the sensor Sentinel $1 \mathrm{~A}$ which is present-day operational and open access.

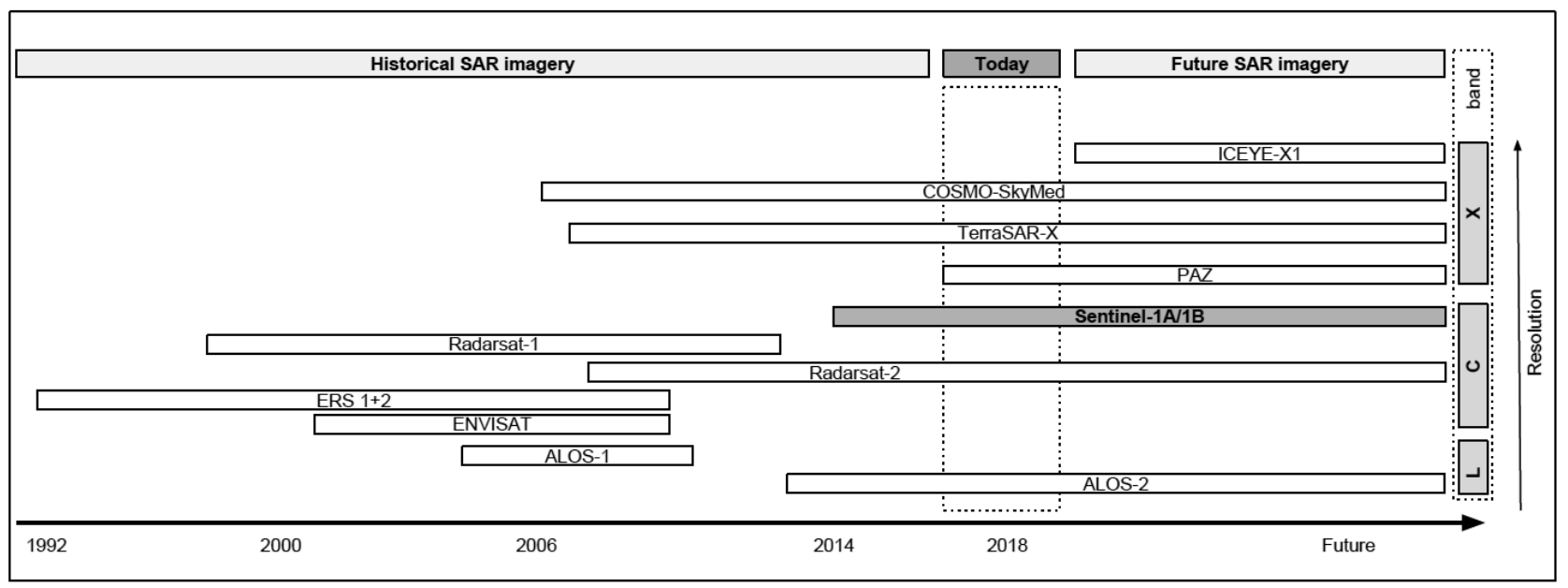

Fig. 1. Historical and present-day active Remote Sensing SAR sensors.

\footnotetext{
* Corresponding author: jaroslaw.wajs@pwr.edu.pl
} 


\section{Motivation}

Open pit lignite mine is an object whose topography changes over time. One of the most important information about this anthropogenic object are vertical displacements. Due to the fact, that the remote sensing allows to acquire high spatial and temporal data, the frequent information about object of interests can be provided. With the development of remote sensing missions of the European Space Agency (ESA), remote sensing data have become a perfect source of information on the state of objects in macro scale. In November 2012 Poland became an ESA member and at the same time a beneficiary of the GMES (Global Monitoring for Environment and Security) programme. The continuation of the GMES is the Copernicus programme, in the frame of which SENTINEL satellites were introduced. The constellation of Sentinel 1A/1B satellites is a source of terrain imageries with high temporal and geometrical resolution accomplished due to specially applied precise orbits, whose precision was determined in 3D at the level of $5 \mathrm{~cm}$ in [3]. The instrument installed on the Sentinel 1 satellite is a Synthetic Aperture Radar operating in band C with 5.65 $\mathrm{cm}$ wavelength. These components allowed for application of SAR data in the monitoring of the study object. The active SAR instrument allows to deliver the detailed and accurate information about ground subsidence. Over the past two decades, InSAR techniques have evolved from the use of differential interferograms (DInSAR) in the late 1990s [4, 5] to Persistent Scatterers Interferometry (PSI) in the $21 \mathrm{st}$ century $[6,7]$. Monitoring of post mining settings was presented by [8] and [9]. There are many methods of SAR data processing, which, along with the development of high resolution SAR satellites such as
TerraSAR-X observing in band $\mathrm{X}$, allow for mine monitoring with high spatial resolution and precision. At first, reports on SAR data processing covered urban agglomerations [10] and underground mines, where stable PSI diffusers are relatively easy to acquire [11, 12]. PSI in fact overcomes limitations related to the atmospheric contributions affecting the standard DInSAR technique and allows millimeter precision to be reached. Monitoring of open pit mines with DInSAR techniques was presented already by $[13,14]$. An open pit mine is a dynamic object that changes its geometry with time. Currently, advanced methods of SAR time series high spatial resolution and frequent temporary acquisition give the opportunity to detect changes from space also in open pit mines $[15,16]$.

\section{Study area}

The analyses were performed in the PGE KWB Belchatow open pit lignite mine located in central Poland, Europe. The KWB Belchatow object comprising two excavation areas named as Belchatow and Szczercow which are presented in the portion of the Sentinel2A false color imagery acquired on 25.05.2016 (Fig. 2). The analyzed region of interests (ROI) overlapped the mining area and the remote sensing data capacity was reduced to this region. The outline of the open pit and the internal dumping site is marked with a yellow rectangle and marked as A. Areas representing the second excavation Szczercow is depicted by B. The ROI including the Szczercow external dumping site and marked as $\mathrm{C}$ was analyzed for possible pseudo-vertical displacements of the terrain. Since analyzed object is an open cast lignite mine, the obtained terrain subsidence is an essential information of mining area.

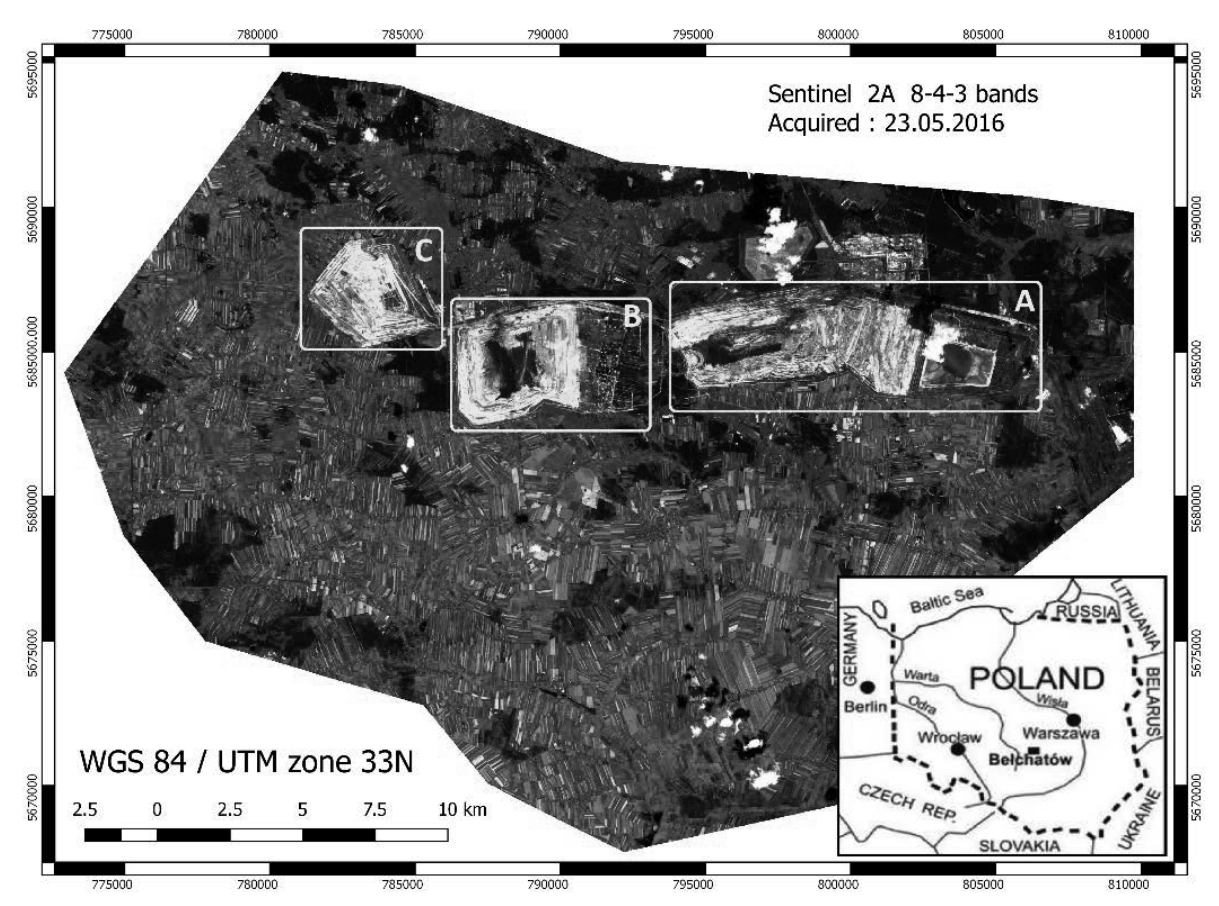

Fig. 2. Portion of Sentinel imagery of the Belchatow open pit lignite mine. The combination is in a false colour 8-4-3 band acquired on 25.05.2016. 
Table 1. The visualization of Sentinel 1A 124-orbit SLC IW1 product is presented at Fig. 3.

\begin{tabular}{|c|c|c|c|c|c|}
\hline $\begin{array}{c}\text { Sentinel } \\
\text { 1A Scene }\end{array}$ & Date of acquisition [date] & Orbits & $\begin{array}{c}\text { Incident } \\
\text { Angle [DEG] }\end{array}$ & Baseline [m] & Temporary resolution [days] \\
\cline { 1 - 4 } SLC IW1 & 03.10 .2016 & 124 descending & $30.86-36.59$ & \multirow{2}{*}{43} & 12 \\
\cline { 1 - 3 } SLC IW1 & $\mathbf{1 5 . 1 0 . 2 0 1 6}$ & $\mathbf{1 2 4}$ descending & $30.86-36.59$ & & \multirow{2}{*}{12} \\
\cline { 1 - 3 } SLC IW1 & 27.10 .2016 & 124 descending & $30.86-36.59$ & 9 & 12 \\
\hline
\end{tabular}

\section{Methodology}

\subsection{Sentinel 1A data preprocessing}

Data subject to analysis were collected from ESA on the SentinelHUB platform (URL: https://scihub.copernicus. $\mathrm{eu} /$ dhus). The processed imagery was obtained by Sentinel 1A on 03.10.2016, 15.10.2016 and 27.10.2016 in a Interferometric Wide Swatch, Single Look Complex standard with VV polarization. Additionally, POD Precise Orbit Ephemerides (URL: https:/qc.sentinell. eo.esa.int) were also collected for these imageries. Details are presented in Table 1.

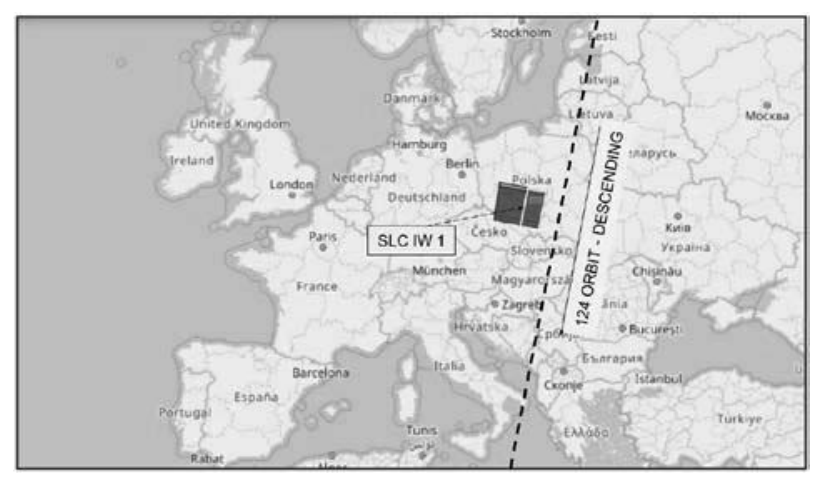

Fig. 3. Visualization of Sentinel 1A 124-orbit SLC IW1 product.

\subsection{DInSAR method description}

Data from the Synthetic Aperture Radar (SAR) of the SENTINEL 1A mission are characterized by high spatial $(5 \times 15 \mathrm{~m})$ and temporal resolution (12 days). Additionally, precise orbits allow the satellite position to be stated precisely and the spatial database B presented in Fig. $4 \mathrm{a}$ to be determined. At maintaining optimal construction requirements, a $3 \mathrm{D}$ reconstruction of the terrain surface is possible, for example in the SRTM mission. The methodology of SAR data processing presented herein is based on Differential SAR Interferometry (DInSAR) (Fig. 4b). It processes a minimum of two SAR imageries collected in time t1 and $\mathrm{t} 2$, respectively, and including the Digital Elevation Model component [18]. The main requirement for accurate processing in DInSAR methodology is to have precise orbits and relatively short temporal and spatial base. The scheme of processing is presented in Fig. 5 . (a)

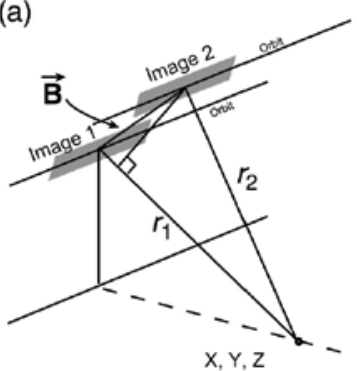

(b)

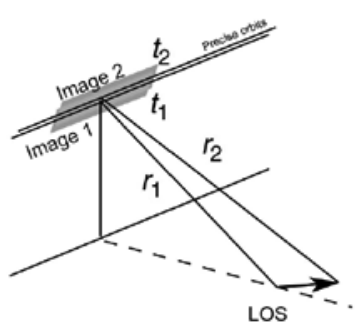

Fig. 4. Method of (a) radargrammetry INSAR DEM generation, and (b) DInSAR LOS displacement detection. Compilation based on [17].

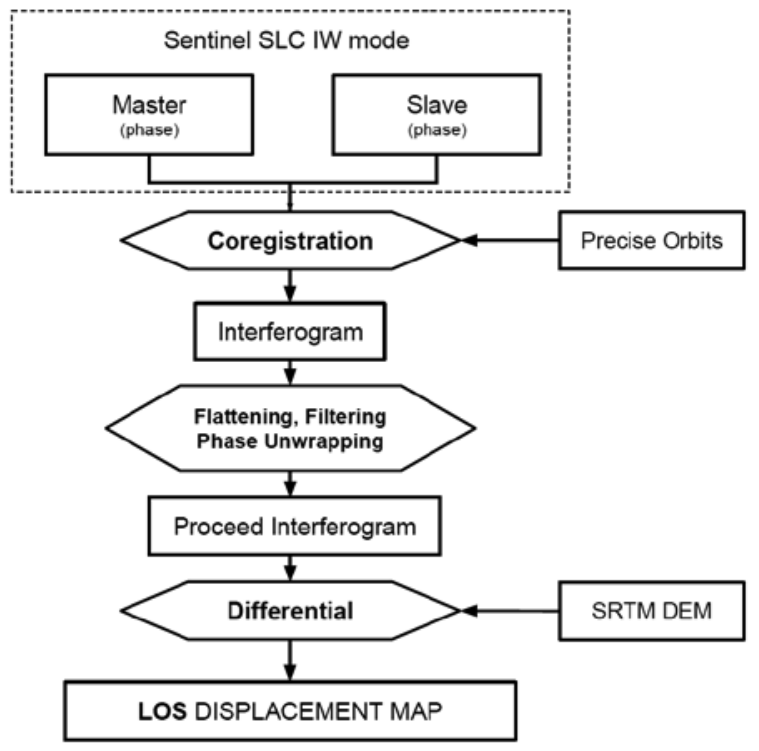

Fig. 5. Methodology of implemented DInSAR approach. Original compilation based on [18].

The data processing was performed in the GMTSAR software package [19], and the results are visualized with QGIS software [20]. The procedure of phase unwrapping was made with application of Snaphu algorithms [21]. Shuttle Radar Topography Mission (SRTM 1) data were used to correct of wave phase with regard to terrain surface [22].

\section{Results}

Since analyzed object is an open pit mine, the obtained map of terrain subsidence is based on a large number of points located in strong coherent regions. The SAR 
signal reflects well from an area uncovered by vegetation, both between 3-15.10.2016 and 15-27.10.2016. The LOS displacement map obtained after DInSAR data processing in the first analyzed internal is presented in Fig. 5. The processing indicates that the maximal subsidence values determined by the DInSAR method are $-42 \mathrm{~mm}$ and occur in area C. This value is marked in green in Fig. 6. The Szczercow dumping site is an area where soil compaction takes place. The C-C' cross-section was generated following the analyses. It shows that the maximal value of terrain subsidence occurs in the top of the dumping site. Regions with potential terrain uplift during the 12 days of the analysis are marked in red. Terrain uplift occurs in excavation B and partly in excavation A, which may indicate relaxation following lignite exploitation.
Subsidence occurs also in area A, in the eastern part of the excavation pit, which probably results from the occurrence of an internal dumping site and compaction of the deposited material.

The second analyzed period was based on imagery acquired between 15.10.2016-27.10.2016. The results of the compilation as Line of Sight (LOS) displacement maps are presented in Fig. 7. The maximal terrain subsidence for the analyzed period was $-25 \mathrm{~mm}$ near the Szczercow dumping site. Moreover, the C-C' crosssection was generated for additional visualization. The maximal value of terrain subsidence occurs also in the top of the dumping site. The fact that soil compaction occurs also in the second study period indicates that the process may be continuous.

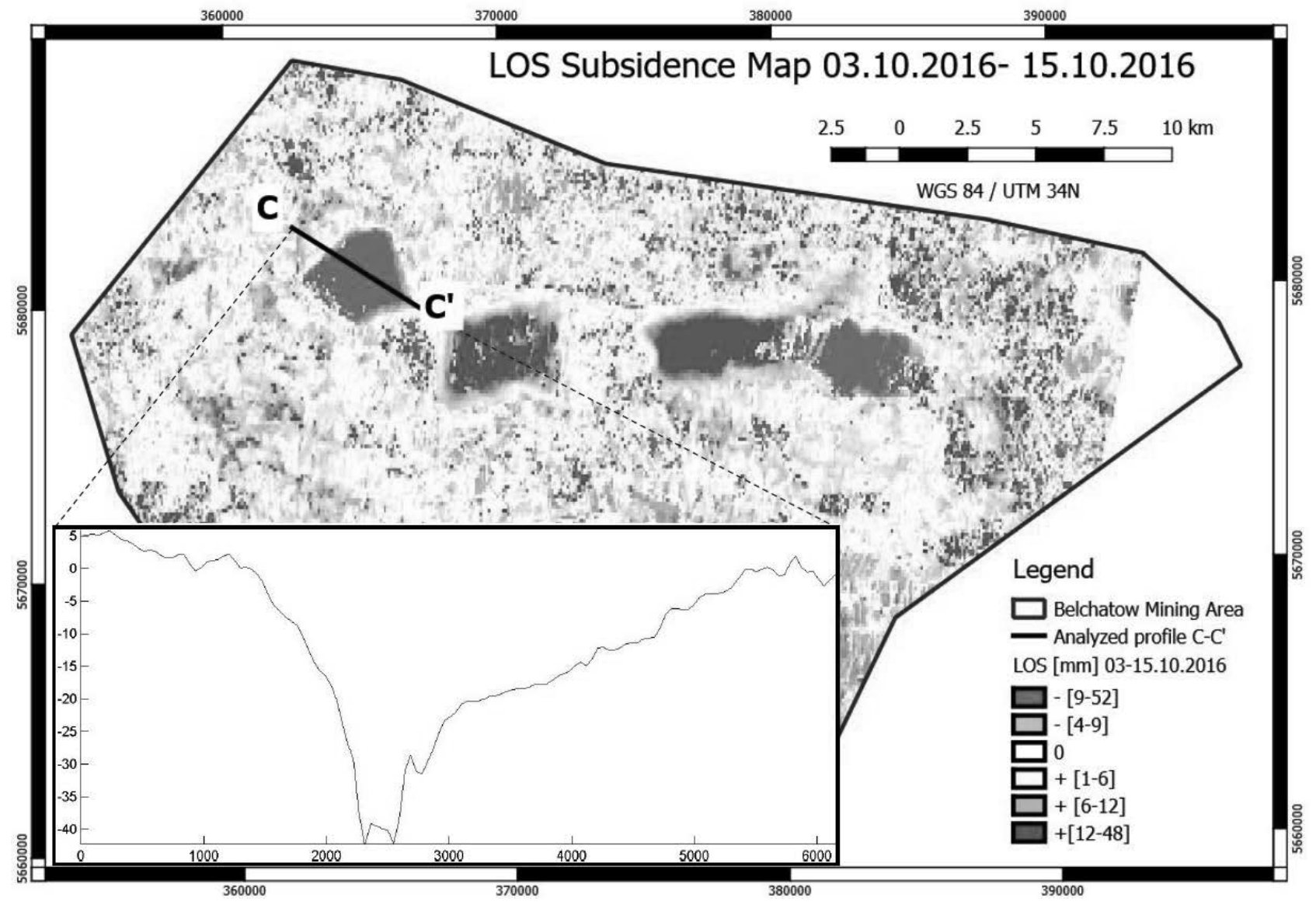

Fig. 6. Visualization of LOS displacements in the UTM system in zone 34N (EPSG: 32634) for a pair of SAR imageries acquired between $03.10 .2016-15.10 .2016$, determined by the DInSAR method. 


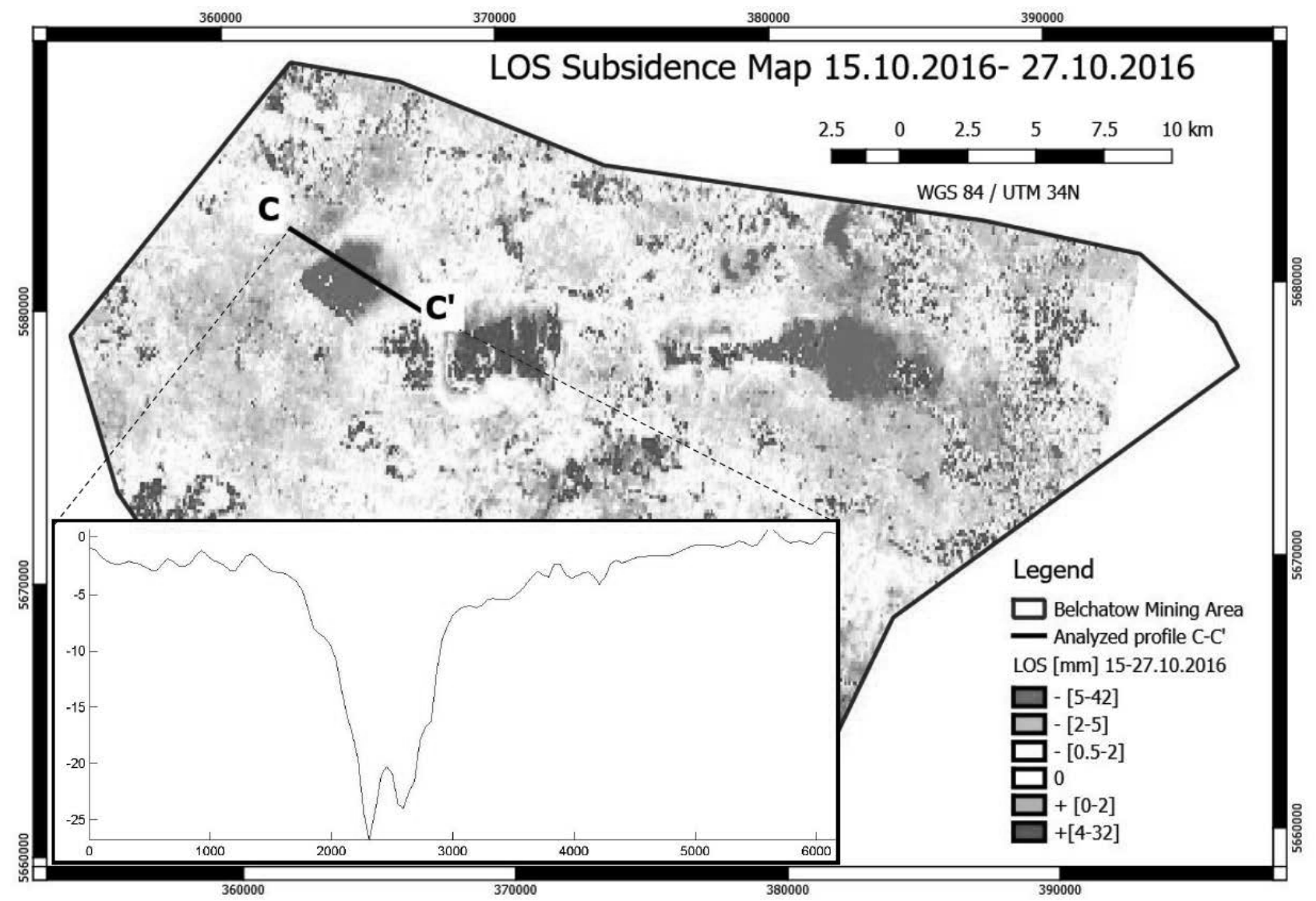

Fig. 7. Visualization of LOS displacements in the UTM system in zone 34N (EPSG: 32634) for a pair of SAR imageries acquired between 15.10.2016-27.10.2016, determined by the DInSAR method.

\section{Summary}

The paper presents the first experimental tests applying SAR imageries for the Belchatow open pit lignite mine. The research was focused on remote sensing sensor selection and elaborating a methodology allowing for correct data processing in a GMTSAR environment for the study object. The chosen Sentinel 1A SAR platform characterized by high temporal resolution was used in the study; in effect highly coherent interferograms were obtained. Areas with a similar characteristics of LOS displacement were registered for the analyzed two periods. These data represent a complete continuous surface information, as opposed to classical point surveys for the analyzed areas. Results of LOS displacement indicates that the Szczercow dumping site marked as $\mathrm{C}$ undergoes compaction in its top. Relaxation of the exposed lignite deposit in the Belchatow and Szczercow (A and B) excavation was also observed. Presented methodology allowed to detect continuous deformations with were presented at cross sections C-C'. The results show that the observed subsidence is relevant and allows to detect potential hazards. Further research will focus on processing of Sentinel $1 \mathrm{~A}$ and $2 \mathrm{~A}$ imageries, which should allow for obtaining a high-temporal resolution. It allows to acquire data every 6 days. More frequent sampling of the Belchatow open cast mine should allow more reliable results of the surface changes in the mining area to be observed. The next step should include data processing with application of time series INSAR analysis and validation of the results based on controlling classical land surveys for accuracy assessment.

This work was financed by the Polish Statutory Research Grant no. 0402/0123/17, 0402/0146/16 and 0402/0011/17.

\section{References}

1. J. Wajs, Mining Science, vol. 22, 75-83 (2015)

2. C. Toth and G. Jóźków, ISPRS Journal of Photogrammetry and Remote Sensing, 115, 22-36 (2016)

3. H. Peter-Contesse, A. Jäggi, J.J. Fernández, D. Escobar, F. Ayuga, D. Arnold, P. Visser, Advances in Space Research, Volume 60, Issue 5, 879-892 (2015)

4. D. Massonnet and K.L. Feigl, Reviews of geophysics, 36(4), 441-500 (1998)

5. C. Carnec, D. Massonnet, C. King, Geophysical Research Letters, 23(24), 3579-3582 (1996)

6. C. Colesanti, S. Le Mouelic, M. Bennani, D. Raucoules, C. Carnec, A. Ferretti. International Journal of Remote Sensing 26:1, 201-207 (2005) 
7. M. Costantini, F. Minati, M.G. Ciminelli, A. Ferretti, S. Costabile, Proceedings of IGARSS 2015, IEEE International Geoscience and Remote Sensing Symposium, Milan, Italy (IEEE Geoscience and Remote Sensing Society, 2015)

8. W. Milczarek, J. Blachowski, P. Grzempowski, Acta Geodyn. Geomater., Vol. 14, No. 1 (185), 4152 (2017)

9. S. Samsonov, N. d'Oreye, B. Smets, International Journal of Applied Earth Observation and Geoinformation, 23, 142-154 (2013)

10. M. Crosetto, M. Castillo, R. Arbiol, Photogrammetric Engineering and remote sensing, 69(7), 775-783 (2003).

11. M. Mroz and Z. Perski, Proceedings of the 22nd Symposium of the European Association of Remote Sensing Laboratories, Prague, Czech Republic, 4-6 June 2002, 621-624 (2003)

12. M. Przyłucka, G. Herrera, M. Graniczny, D. Colombo, M. Béjar-Pizarro, Remote Sensing, 7(5), 5300-5328 (2015).

13. V.D. Poenaru, I.F. Dana Negula, A. Badea, R. Cuculici, The International Archives of the Photogrammetry, Remote Sensing and Spatial Information Sciences, Volume XLI-B8, XXIII ISPRS Congress, 12-19 July 2016, Prague, Czech Republic (2016)

14. E. Papadaki A. Tripolitsiotis, Ch. Steiakakis, Z. Agioutantis, M. Stelios, P. Partsinevelos, P. Schilizzi, Proc. First International Conference on Remote Sensing and Geoinformation of the Environment, Vol. 8795, 87951A (2013)

15. D. Colombo and B. MacDonald, Proceedings of the SAIMM International Symposium on Slope Stability in Open Pit Mining and Civil Engineering, Cape Town, South Africa (2015)

16. C. Ma, X. Cheng, Y. Yang, X. Zhang, Z. Guo, Y. Zou, Remote Sensing, 8(11), 951 (2016)

17. P.A. Rosen, S. Hensley, I.R. Joughin, F.K. Li, S.N. Madsen, E. Rodriguez, R.M. Goldstein, Proceedings of the IEEE, 88(3), 333-382 (2000).

18. A. Ferretti, C. Monti-Guarnieri, F. Prati, InSAR Principles: Guidelines for SAR Interferometry Processing and Interpretation (ESA Publications, 2007)

19. D.T. Sandwell, R.J. Mellors, X. Tong, M. Wei, P. Wessel, AGU Fall Meeting Abstracts (2010)

20. QGIS Development Team. QGIS Geographic Information System. Open Source Geospatial Foundation Project, http://qgis.osgeo.org (2018)

21. C.W. Chen and H.A. Zebker, J. Opt. Soc. Am. A, 17, 401-414 (2000)

22. J.A. Slater, G. Garvey, C. Johnston, J. Haase, B. Heady, G. Kroenung, J. Little, Photogrammetric Engineering and Remote Sensing 72(3), 237-247 (2006) 